\title{
On the A. Malaris of the Goat (Capra hircus)
}

\author{
By
}

\author{
Yukiyasu Suzuki and Hitoshi Okuda \\ Department of Anatomy, Osaka Dental University \\ 5-31, Otemae 1-chome, Chuo-ku, Osaka 540, Japan \\ (Director: Prof. Yoshikuni Ohta)
}

- Received for Publication, September 21, 1990-

Key Words: Arteria malaris, Infraorbital artery, Blood supply, Plastic injection, Goat

\begin{abstract}
Summary: Detailed observations were made of the a. malaris in 25 adult goats by means of the acryl plastic injection method and the findings obtained were evaluated in comparison with those for other mammals. The malar artery arose from the superior wall of the infraorbital artery, lateral to the infraorbital nerve and superomedial to the maxillary tuber, independently or rarely in common with the superior alveolar artery. It first passed anterolaterally in the sulcus malaris on the superior surface of the lacrimal bulla and gave rise to the third palpebral branch independently or rarely in common with the inferior oblique muscular branch beneath the obliquus inferior muscle, and also the main and accessory inferior oblique and the maxillary sinus branches. The third palpebral branch gave off the periosteal, the conjunctive, the supero- and inferolateral branches. After the malar artery gave off the zygomatic branch on the orbital surface of the zygomatic bone, it passed anterosuperiorly up to the incisura malaris at the medial end of the infraorbital margin of the lacrimal bone and gave off the medial superior and inferior palpebral arteries or a common trunk between them. It continued to pass forwards as the nasal radical branch after giving off the infraorbital marginal branch and anastomosed with the nasal dorsal branch of the superficial temporal artery. The medial inferior palpebral artery formed the inferior palpebral arterial arch by anastomosing with the lateral inferior palpebral artery of the superficial temporal at the lateral canthus. The inferior palpebral marginal, the ocular orbicular muscular and the conjunctive branches diverged from the above arterial arch. The medial superior palpebral artery gave off the lacrimal canalicular and the nasolacrimal canal branches and anastomosed with the lateral superior palpebral artery or the frontal branch of the superficial temporal at the medial canthus. The characteristic features of the malar artery in the goat were thus the third palpebral branch occasionally diverging from the external ophthalmic artery of the maxillary artery, a main and several accessory inferior oblique muscular, the maxillary sinus branches and the zygomatic branches.
\end{abstract}

The a. malaris as one of the branches supplying the orbital contents was not found in textbooks of human anatomy but was mentioned in the Nomina anatomica veterinaria (1978) and in books on mammalian anatomy. Recently, detailed observations of this artery have been made in the dog by Arai (1978), the cat by Inazuka (1986), the rabbit by Miyake (1987), the Japanese monkey by Otsuka (1988) and the common squirrel monkey by Ishidoh (1989). Some differences have been found in the morphology of the malar artery between these mammalian species according to the form of the orbit, its contents and supply routes to them.

The present paper reports detailed observations for the a. malaris in the goat, a ruminant species, and the findings obtained are discussed in comparison with those reported for other mammals by previous workers.

\section{Materials and Methods}

Twenty-five adult goats (Capra hircus) were used in this study. Acryl plastic was injected into the common carotid arteries by the plastic injection method (Taniguchi, Ohta et al., 1952, 1955). Twenty of the injected heads were prepared to give vascular casts of the carotid system by treatment with $20 \%$ sodium hydroxide solution. The remaining 5 injected heads were preserved in $10 \%$ formalin solution to provide dissection specimens. Observations and measurements were performed on all the 25 heads ( 50 sides) under a binocular microscope.

\section{Findings}

I. General aspect of the a. malaris (malar artery) (Figs. 1-6)

The malar artery $(0.8-1.1, M .0 .93 \mathrm{~mm}$ in diameter) arose anterosuperiorly or antero-superomedially from the superior wall of the infraorbital artery $(1.1-1.6, M .1 .30 \mathrm{~mm}$ in diameter), lateral to the infraorbital nerve and superomedial to the maxillary 
tuber (Figs. 3-5), independently in 46 of the 50 examples observed and in common with the superior alveolar artery in the other 4 (Fig. 6). This artery immediately bent anterolaterally to pass in a groove, termed the sulcus malaris in this paper, on the superior surface of the lacrimal bulla (into which part of the maxillary sinus extended) of the lacrimal bone (Fig. 2). It ran anterosuperiorly between the venter of the obliquus inferior muscle and the orbital surface of the zygomatic bone up to an incisura, termed the incisura malaris in this paper, on the infraorbital margin of the lacrimal bone (Fig. 2), where the malar artery divided into a common trunk between the medial superior and inferior palpebral arteries and the nasal radical branch as a terminus of the malar artery. En route, the artery gave rise to the third palpebral, the inferior oblique muscular, the maxillary sinus, the zygomatic and the nasolacrimal canal branches (Fig. 1).

\section{Ramifications}

1. Third palpebral branch

The branch $(0.4-0.5$, M. $0.42 \mathrm{~mm}$ in diameter) arose forwards from the medial wall of the malar artery in the malar groove, independently in 28 examples (Figs. $3,4)$ and in common with the inferior oblique muscular branch in 6 . In 15, this branch arose from the medial rectal muscular branch of the external ophthalmic artery (Fig. 9). In the remaining one case, this branch was two in number; each of them arising from the medial rectal branch and the malar artery, respectively. The latter supplied the inferior half of the third palpebra.

The third palpebral branch passed forwards outside the periorbita of the lacrimal bulla and superoanteriorly on the obliquus inferior muscle and gave off the periosteal (Figs. 8, 9) and the conjunctive branch at the inferior margin of the third palpebral gland, where the inferolateral branch diverged. It still continued to pass posteromedially along the gland up to its superior margin, where the superolateral branch diverged. It finally ran within the extraperiorbital adipose body anterosuperiorly anastomosing with the medial rectal branch (Fig. 8).

i) Periosteal branch

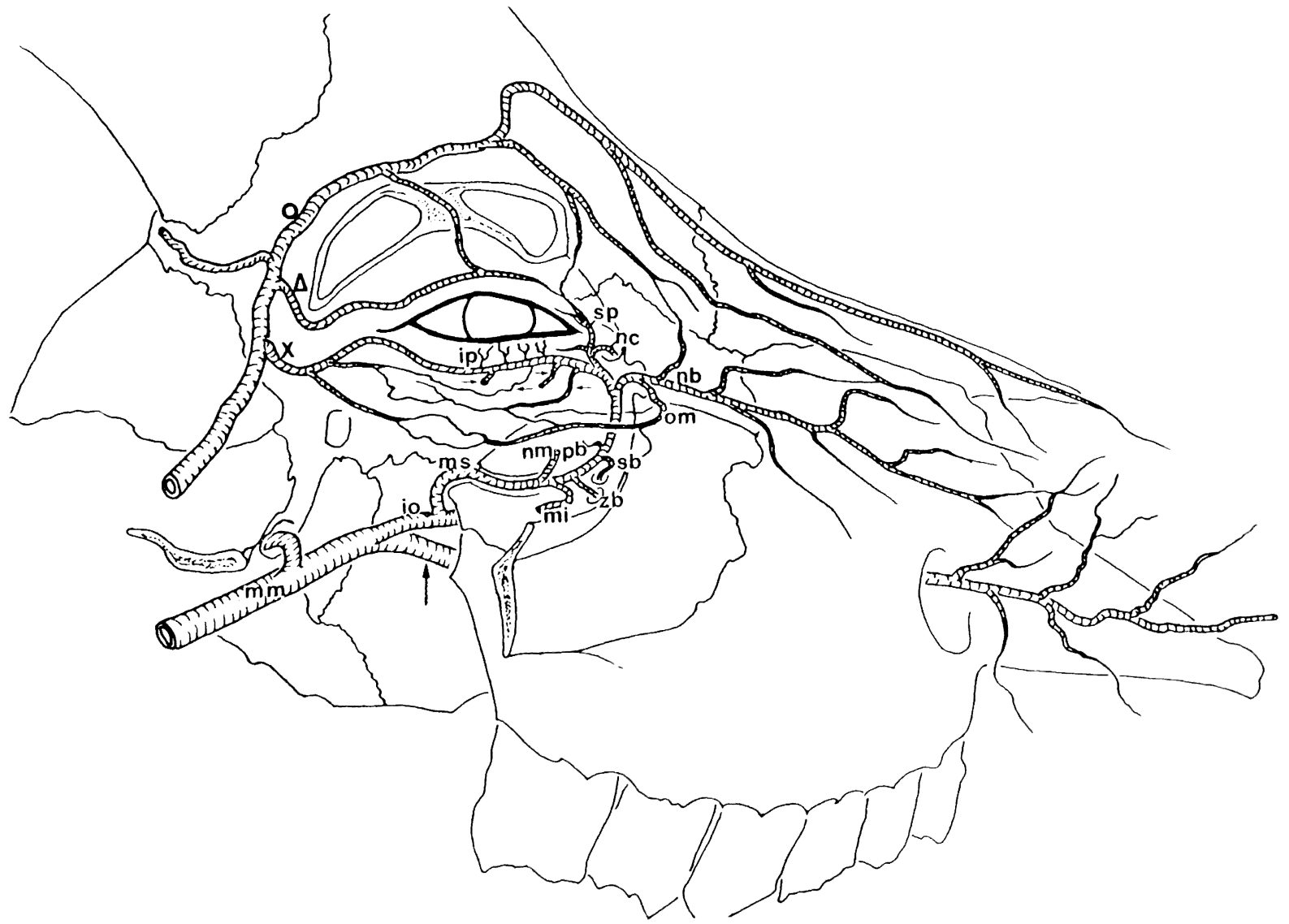

Fig. 1. Schematic drawing of the a. malaris of the goat, right side.

io: Infraorbital artery, ip: medial inferior palpebral artery, mi: inferior oblique muscular branch, mm: maxillary artery, ms: a. malaris, nb: nasal radical branch, nc: nasolacrimal canal branch, nm: third palpebral branch, om: infraorbital marginal branch. pb: periosteal branch, sb: maxillary sinus branch, sp: medial superior palpebral artery, zb: zygomatic branch, 0 : frontal branch of the superficial temporal artery, $\Delta:$ lateral superior palpebral artery, $\quad$ : lateral inferior palpebral artery, $\uparrow:$ sphenopalatine artery, $\leftarrow$ : ocular orbicular branch, $\rightarrow$ : conjunctive branch. 
This branch (124-434, M. $279 \mu \mathrm{m}$ in diameter), observed in 13; diverged from the third palpebral branch in 7 (Figs. 7,8) and directly from the malar artery in 6 . It passed upwards on the origin of the obliquus inferior muscle outside the periorbita and medial to the parent branch, supplying this muscle, the periosteum in an area above the muscle and extraperiorbital adipose body. In other 7 , this branch extended upwards as the nasolacrimal canal branch and entered the same named canal via the posteromedial end of its orbital orifice.

\section{ii) Conjunctive branch}

This branch $(248-310$, M. $279 \mu \mathrm{m}$ in diameter), observed in all examples, diverged from the third palpebral in 30 (Figs. 7, 8), directly from the malar artery in 11 (Fig. 12) and from the inferior oblique branch in the other 9 . It passed superolaterally outside the periorbita up to the superior margin of the obliquus inferior muscle, where the muscle penetrated the periorbita to enter the orbital muscular pyramid. It supplied the medial part of the inferior palpebral conjunctiva and the muscle.

iii) Superolateral and inferolateral branches

The former and latter branches (155-372, M. 250 $\mu \mathrm{m}$ and $124-248$, M. $209 \mu \mathrm{m}$ in diameter, respectively) passed along the superior and inferior margins, respectively, of the third palpebral cartilage supplying it, and were distributed finally to the superior and inferior halves, respectively, of the third palpebra (Fig. 8).

2. Inferior oblique muscular branches.

These branches were found to comprise one main (310-490, M. $378 \mu \mathrm{m}$ in diameter) and 1-3 accessories (124-310, M. $216 \mu \mathrm{m}$ in diameter).

The main muscular branch, observed in all examples, arose anterolaterally, independently from the lateral wall of the malar artery distal to the origin of the third palpebral branch in 39 (Figs. 3, 4, 7, 8) and anteriorly in common with the third palpebral branch in 6 and from the external ophthalmic artery in 5 (Fig. 10). It passed superolaterally on the lacrimal bulla, supplying the lacrimal bone, sinus and extraperiorbital adipose tissue, to enter the venter of the obliquus inferior muscle from its inferior border at this portion where the muscle penetrated the periorbita (Fig. 4). After giving off small twigs to its origin, the branch ran within the muscle towards its insertion to supply the inferior smooth muscle (Acheson, 1938) and the inferior palpebral fornix, anastomosing with the conjunctive branch of the medial inferior palpebral artery. The main branch arising from the ophthalmic artery in the above 5 cases passed anterolaterally and entered the muscle in a similar area (Fig. 10), and formed part of the perilimbal vascular arcades (Ruskell, 1962) in the eyeball entering from its insertion.

The accessory muscular branches, observed in 32 , were found to be small ramifications arising anteromedially from the malar artery (Figs. 4, 9, 10, 12) when it ran between the zygomatic bone and the obliquus inferior muscle. They, after giving off twigs to its insertion, passed anteromedially towards its origin and supplied the periorbita of the lacrimal bone.

\section{Maxillary sinus branches}

These branches $(62-341$, M. $181 \mu \mathrm{m}$ in diameter), observed in 13 of all examples, arose from the inferior wall of the malar artery (Figs. 3, 6, 11) in the malar sulcus and entered the superolateral wall of the maxillary sinus passing through small foramina of the bulla.

\section{Zygomatic branches}

These branches (217-372, M. $292 \mu \mathrm{m}$ in diameter), observed in 21 of all examples, and numbering 2 occasionally, arose antero-infero-medially from the inferior wall of the malar artery (Figs. 3, 6, 10, 11) on the orbital surface of the zygomatic bone, and supplied it and the maxillary sinus. In 5 , the branch passed forwards to supply the nasolacrimal canal and in other 5 supplied the maxilla passing through the zygomaticomaxillary suture.

\section{Medial inferior palpebral artery}

This artery (310-558, M. $430 \mu \mathrm{m}$ in diameter) arose superolaterally from the superior wall of the malar artery via a common trunk with the medial superior palpebral artery in 35 (Figs. 4, 6, 11-13) and independently in 15 (Fig. 14). The common trunk passed superolaterally as the medial inferior palpebral artery after giving off the medial superior palpebral artery upwards at the inferior margin of the inferior lacrimal canaliculus and gave rise to the nasolacrimal canal branch in 3 and the infraorbital marginal branch in 5. This artery passed superolaterally along the inferior lacrimal canaliculus and tortuously along the inferior margin of the inferior palpebral gland deeply in the orbicularis oculi muscle, after giving off the nasolacrimal canal branch in one and the infraorbital marginal branch in 4 . It finally formed the inferior palpebral arterial arch by anastomosing with the lateral inferior palpebral artery of the superficial temporal artery. Abundant inferior palpebral marginal branches left this arterial arch upwards, as well as several ocular orbicular and the conjunctive branches downwards.

i) Inferior palpebral marginal branch

The branch (62-186, M. $122 \mu \mathrm{m}$ in diameter) (Fig. 1) arose from the superior wall of the inferior palpebral arterial arch. It divided immediately into the superficial 
and deep twigs, which ran along the palpebral gland towards the palpebral margin. These twigs sometimes arose from the parent artery directly, the ocular orbicular or the conjunctive branch. Both anastomosed with each other in some cases.

\section{ii) Ocular orbicular branches}

This branch (186-279, M. $227 \mu \mathrm{m}$ in diameter) (Fig. 1) arose inferolaterally from the inferior wall of the inferior palpebral arterial arch and rarely gave rise to the conjunctive and the palpebral marginal branches. It supplied the orbicularis oculi muscle descending in it and the skin of the inferior palpebra, anastomosing with the infraorbital marginal and other muscular branches from other arterial routes.

\section{iii) Conjunctive branches}

These branches (93-155, M. $124 \mu \mathrm{m}$ in diameter) (Fig. 1) arose from the inferior wall of the inferior palpebral arterial arch, or rarely the ocular orbicular branch. They descended tortuously to supply the palpebral conjunctiva, anastomosing with the inferior oblique and inferior rectal branches.

\section{Medial superior palpebral artery}

This artery $(155-434$, M. $324 \mu \mathrm{m}$ in diameter) arose superolaterally in common with the medial inferior palpebral in 35 (Figs. 4, 6, 11, 12, 13) and superiorly from the superior wall of the malar artery distal to the origin of the medial inferior palpebral artery in 15 (Fig. 14). It passed upwards across and in front of the lacrimal canaliculi up to the superior lacrimal point, where it terminated by anastomosing with the lateral superior palpebral and the frontal branch of the superficial temporal artery. From this artery, the lacrimal canalicular branches and nasolacrimal canal branch diverged in 33 .

\section{i) Lacrimal canalicular branches}

These branches $(93-125$, M. $116 \mu \mathrm{m}$ in diameter) (Fig. 12) arose superolaterally or antero-infero-medially when the parent artery passed in front of the lacrimal canaliculi, along which passed to supply the medial canthus and lacrimal sac.

ii) Nasolacrimal canal branch

This branch (124-310, M. $217 \mu \mathrm{m}$ in diameter) (Fig. 12), observed in 47 of all examples, arose from the medial superior palpebral artery in 33 , from the common trunk between the medial superior and inferior palpebral arteries in 3 and directly from the malar artery in 3, and from the medial inferior palpebral artery in one. It passed antero-infero-medially along the inferior lacrimal canaliculus to supply it and the lacrimal sac and entered the orbital orifice of the nasolacrimal canal. In 5 cases, it anastomosed en route with peripheral twigs of the zygomatic branch and sphenopalatine artery (Fig. 6). In 7 cases, peripheries of the periosteal branch became the nasolacrimal canal branch (Figs. 7, 8).

\section{Nasal radical branch}

This branch (372-682, M. $473 \mu \mathrm{m}$ in diameter) emerged onto the face after passing through the malar incisura, continued anteromedially between the orbicularis oculi muscle and the lacrimal bone, and bent forwards at the anterior margin of the muscle in the subcutis. It en route gave rise to the infraorbital marginal branch in 41 cases (Figs. 13, 14). The main stream of this branch ran forwards on the anterior surface of the malaris muscle (Fig. 14), giving off small twigs to the nasal radix, where it anastomosed with the opposite fellow and the nasal dorsal artery of the superficial temporal artery.

The infraorbital marginal branch (217-372, M. 323 $\mu \mathrm{m}$ in diameter) arose postero-infero-laterally from the nasal radical branch in 41 (Figs. 13, 14), from the common trunk between the medial superior and inferior palpebral arteries in 5, and from the medial inferior palpebral in 4 . It passed backwards along the infraorbital margin in the orbicularis oculi muscle, anastomosing with the same named muscular branch, the cutaneous branches of the lateral inferior palpebral artery and the inferior palpebral arterial arch.

\section{Discussion}

Detailed findings for the malar artery have recently been reported in the dog by Arai (1978), the cat by Inazuka (1986), the rabbit by Miyake (1987), the Japanese monkey by Ohtsuka (1988) and the common squirrel monkey by Ishidoh (1989). The a. malaris has been listed in veterinary textbooks (Nickel et al. 1954, 1976) and Nomina anatomica veterinaria (1978). However, no detailed morphology of this artery in ruminants has been described in the literature, except for brief statements regarding its parent artery, viz., the infraorbital artery.

The malar artery is generally a branch of the infraorbital artery in most mammals. The location of its origin is always near the proximal orifice of the infraorbital canal. However, it in the goat is located posterior to the orifice, that is, at a position superomedial to the maxillary tuber. The inferior wall of the orbit in the goat is not constructed by the maxilla but by the lacrimal bulla (Sisson et al., 1956) in its anteromedial area. The posterolateral area of the orbital wall is lacking in osseous elements, so the course of the infraorbital artery can not be fixed on an osseous wall and the location of its origin may naturally move backwards. The malar artery in the goat does not arise in common with other vessels (with the exception of 
Table 1. Comparative aspects of the a. malaris in several mammals

\begin{tabular}{lcccccc}
\hline & Dog & Cat & Rabbit & Japanese monkey & $\begin{array}{c}\text { Common squirrel } \\
\text { monkey }\end{array}$ & Goat \\
& (Arai 1978) & (Inazuka 1986) & (Miyake 1987) & (Otsuka 1988) & (Ishidoh 1989) & $\begin{array}{c}\text { (Present authors } \\
1990)\end{array}$ \\
\hline 1. Parent artery & & & Infraorbital artery & & Superomedial to \\
the maxillary tuber
\end{tabular}

+++ : All cases, $++:$ more than $50 \%,+$ : less than $50 \%, \pm:$ less than $10 \%,-:$ defective, ${ }^{*}$ : main and accessory.

NOTE: Ishidoh's table (1989) has been modified by adding the present findings.

arising in common with the superior alveolar artery in only 4 of the present cases), as is seen on the malar artery often arising in common with the anterior nasal dorsal artery of the cat, dog and rabbit as well as the anterior superior alveolar artery of the cat. One characteristic feature in the goat is the groove and incisura which are sculptured for the malar artery on the superior surface of the lacrimal bulla: These impressions were termed the sulcus and incisura malaris respectively, in this paper.

The ramifications of the malar artery are summarized in Table 1 in comparison with data reported for other mammals by previous authors. The infraorbital nerve branch which virtually always exists in mammals, is not observed in the goat. This is the reason why the infraorbital nerve and artery of the goat follow a deep course separating from the inferior wall of the orbita, due to the existence of a large lacrimal bulla The third palpebral branch is well developed in about two-thirds of all examples observed, as seen in the cat and common squirrel monkey, but is absent in the remaining one third, in the dog and Japanese monkey, this branch is not found despite the existence of the third palpebra. In the goat, the third palpebra is supplied by a similar branch arising from the external ophthalmic artery when the branch does not diverge from the malar artery. The inferior oblique branch constitutes a stout and constant branch of the malar artery. Its number and distribution territory show some differences in other species, although this branch is only an important route for the obliquus inferior muscle.
The peripheries of this branch in the goat extend into the eyeball and form the perilimbal vascular arcades as reported by Ruskell (1962) in the rabbit. The infraorbital marginal branch is a direct branch of the malar artery in the rabbit, Japanese monkey and common squirrel monkey, from the medial inferior palpebral branch in the dog and from the nasal radical branch in the goat. The lacrimal sac branch does not diverge directly from the malar artery in the goat and Japanese monkey but the sac is supplied by the nasolacrimal canal branch, which is an indirect branch of the artery as seen in other mammals but of the medial superior palpebral in the goat. The nasal radical branch of the goat is rather well developed as a course continuation of the malar artery since the nasal radix appears a long slope. The medial superior and inferior palpebral arteries are well developed as observed in the cat, rabbit and common squirrel monkey, although both are absent in the crab-eating monkey. The medial superior palpebral artery does not represent a main supply route for the upper eyelid in the goat, although Prince et al. (1960) have indicated as a main route, but terminates around part of the medial canthus as seen in the dog. The maxillary sinus branch and the zygomatic branch are characteristic ramifications which have not been reported in the other species.

As regards the termini of the malar artery in the goat, it can be said that its terminus is the nasal radical branch because it was constantly well developed in all the examples observed. Although this branch has been reported in the other mammals except the crab-eating 
monkey, it usually is underdeveloped with a narrow distribution territory.

\section{Acknowledgments}

The authors wish to express their sincere gratitude to Professor Yoshikuni Ohta for critically reading this manuscript, and to all staff members of the Department of Anatomy for their invaluable assistance.

\section{Literature cited}

1) Acheson, G.: The topographical anatomy of the smooth muscle of the cat's nictitating membrane. Anat. Rec., 71: 297-310, 1938.

2) Arai, M.: On the a. malaris of the dog. Okajimas Folia Anat. Jpn., 54: 361-376, 1978.

3) Inazuka, H.: On the a. malaris of the cat. Shika Kiso Igakkai Zasshi (Jpn. J. Oral Biol.), 28: 633-645, 1986 (in Japanese).

4) Ishidoh, E.: On the a. malaris of the common squirrel monkey (Saimiri sciureus). Okajimas Folia Anat. Jpn., 66: 113-132, 1989.
5) Miyake, $\mathrm{H}$.: On the a. malaris of the rabbit. Shika Kiso Igakka Zasshi (Jpn. J. Oral Biol.), 29: 44-57, 1987 (in Japanese).

6) Nickel, R., A. Schummer \& E. Seiferle: Lehrbuch der Anatomie der Haustiere. Bd. I, Verlag Paul Parey, Berlin, 120-121, 1954

7) Ditto: Ibidem. Bd. III, 108-121, 1976.

8) Nomina anatomica veterinaria: Published by Intern. Comm. on Veterin. Anat. Nomen., 2nd ed., revised in 1975, Holzhausen's Succ., 1978.

9) Otsuka, T.: On the a. malaris of the Japanese monkey (Macaca fuscata fuscata). Shika Kiso Igakkai Zasshi (Jpn. J. Oral Biol.), 30: 431-442, 1988 (in Japanese).

10) Prince, J. H., C. D. Diesem, I. Eglitis \& G. L. Ruskell: Anatomy and histology of the eye and orbit in domestic animals. Thomas Co., Springfield, I11., 182-209, 1960.

11) Ruskell, G.L.: Anterior communications between the intrinsic and extrinsic arteries of the rabbit eye. Anat. Rec., 142: 147-154, 1962.

12) Sisson, S. \& J. D. Grossman: Anatomy of the domestic animals. 4th. ed., Saunders Co., Phila., 160, 138, 139, 1956.

13) Taniguchi, Y., Y. Ohta \& S. Tajiri: New improved method for injection of acrylic resin. Okajimas Folia Anat. Jpn., 24: 259-267, 1952.

14) Taniguchi, Y., Y. Ohta, S. Tajiri, H. Okano \& H. Hanai: Supplement to new improved method for injection of acrylic resin. Okajimas Folia Anat. Jpn., 27: 401-406, 1955.

Key to abbreviations in figures

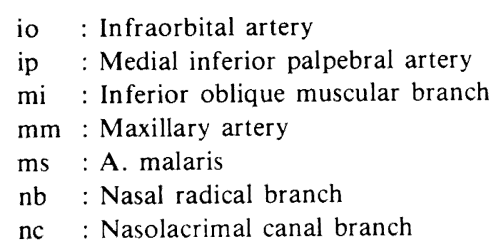

\section{Explanation of Figures}

\section{Plate I}

Fig. 2. Superior view of the inferior wall of the orbit, right side. $\times 1.5$

Part of the inferior wall is formed by the lacrimal bulla ( $*)$ of the lacrimal bone $(X)$. The sulcus malaris $(\uparrow)$ and numerous small foramina are observed on the superior surface of the bulla, and the incisura malaris ( $\longleftarrow$ ) on the medial margin of the orbit. $\rightarrow$ : Orbital orifice of the nasolacrimal canal, $\bigcirc:$ orbital surface of the zygomatic bone.

Fig. 3. Lateral view of the malar artery, left side. $\times 1$

The malar artery (ms) arises independently from the infraorbital artery.

0 : Alveolar process, $\leftarrow$ : superior alveolar artery, $X$ : nasolacrimal canal.

Fig. 4. Inferior view of the malar artery, left side. Dissection specimen. $\times 2$

The malar artery (ms) gives rise to the third palpebral $(\mathrm{nm})$, the main (mi), and accessory ( $\uparrow$ ) inferior oblique branches. It becomes the nasal radical branch $(\mathrm{nb})$ and emerges onto the face after giving off a common trunk ( $\rightarrow$ ) between the superior and inferior medial palpebral arteries. The position where the obliquus inferior muscle ( $*$ ) penetrates the periorbita ( $O$ ) and enters the orbital muscular pyramid (dotted line).

$X$ : Infraorbital nerve, $\Delta$ : maxillary nerve, $O$ : sphenopalatine artery.

Fig. 5. Frontal section through the origin of the malar artery, right side. $\times 3$

The malar artery $(\mathrm{ms})$ passes lateral to the infraorbital nerve $(\leftarrow)$. Dotted line: Inferior orbital wall, $\bigcirc:$ rectus inferior muscle, $\quad X$ : zygomatic bone, A: masseter muscle, B: pterygoideus medialis muscle, C: eyeball, D: maxilla and 3rd molar,

$\uparrow$ : no osseous area in the orbital wall,

* : posterior end of the lacrimal bulla 

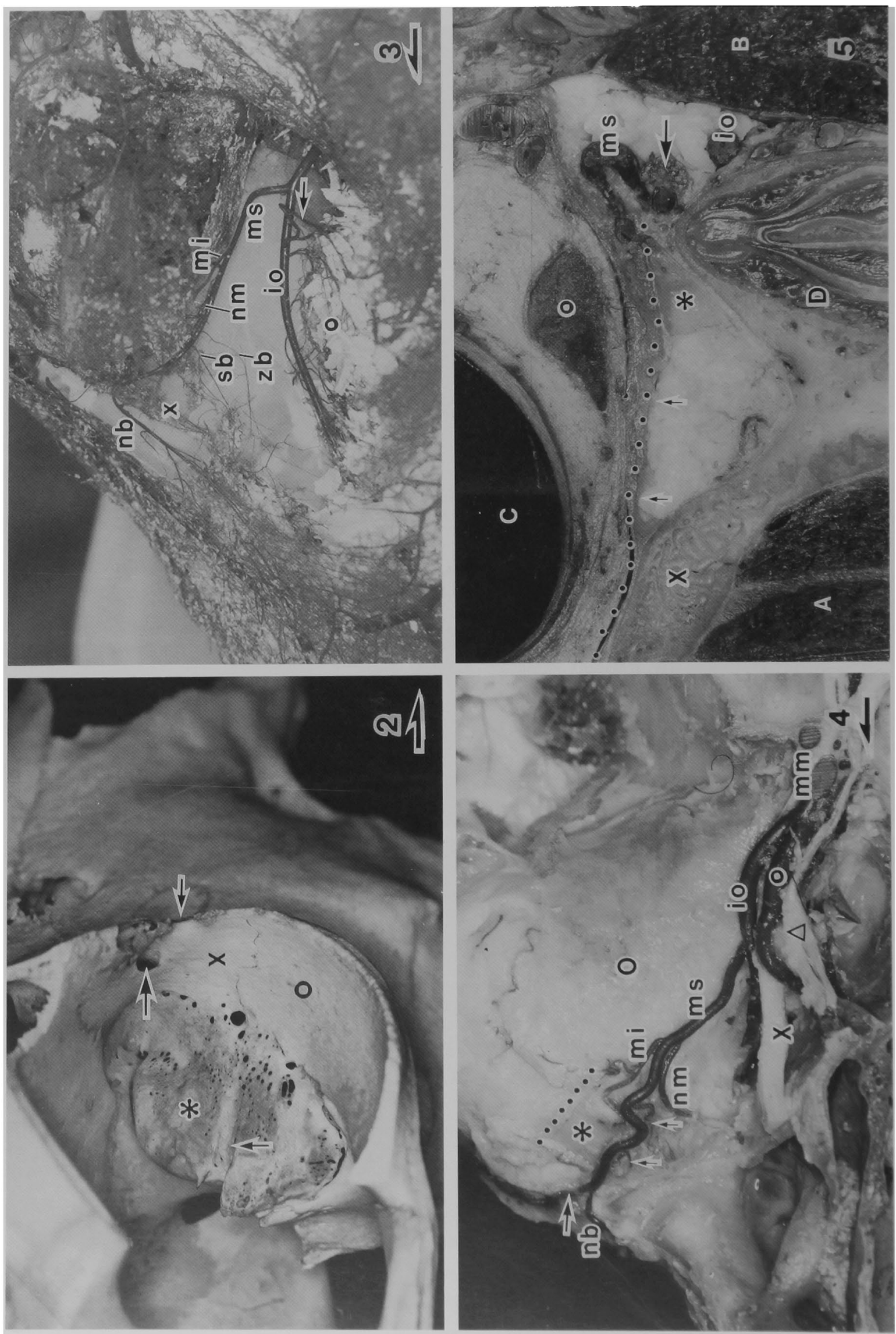


\section{Plate II}

Fig. 6. Lateral view of the malar artery, right side. $\times 2$

The malar artery (ms), arising in common with the superior alveolar artery ( $\downarrow$ ), becomes the nasal radical branch as its terminus after giving off a common trunk between the medial superior (sp) and inferior (ip) palpebral arteries.

A: Palpebral fissure, B: nasolacrimal canal, D: alveolar process, $\uparrow, \rightarrow:$ sphenopalatine artery and nasolacrimal canal branch of it, respectively.

Fig. 7. Inferior view of the orbital muscular pyramid, right side. Dissection specimen. $\times 3$

The obliquus inferior muscle $(\mathrm{M})$ has been rolled upwards to show the third palpebral branch $(\mathrm{nm})$, which gives rise to the periosteal $(\rightarrow)$ and conjunctive $(\leftarrow)$ branches. The former extends into the nasolacrimal canal $(B)$ as the nasolacrimal canal branch. A: Palpebral fissure.

Figs. 8 and 9. Anterior views of the arterial supply of the third palpebra, right side. Dissection specimen. $\times 1.5$

In Fig. 8, the anterior surface of the third palpebra in Fig. 7 is shown. The third palpebral branch (nm) anastomoses with the peripheries of the medial rectal branch $(X)$ after giving off the infero- $(\uparrow)$ and supero- $(\downarrow)$ lateral branches. $*$ : Third palpebra.

In Fig. 9, the malar artery $(\mathrm{ms})$ does not give off the third palpebral branch, but the medial rectal branch $(X)$ supplies the third palpebra in the fashion of the supero- $(\downarrow)$ ) and infero- $(\uparrow)$ lateral branches. $O$ : Accessory inferior oblique branches.

Fig. 10. Inferior view of ramifications of the malar artery and the inferior oblique branch, left side. Dissection specimen. $\times 2$

The malar artery $(\mathrm{ms})$ gives rise to the zygomatic $(\mathrm{zb})$ and accessory inferior oblique $(\mathrm{O})$ branches. The obliquus inferior muscle (M) is supplied by the peripheries ( $*$ ) of the inferior rectal branch. B: Nasolacrimal canal branch, C: infraorbital nerve, E: rectus inferior muscle. 


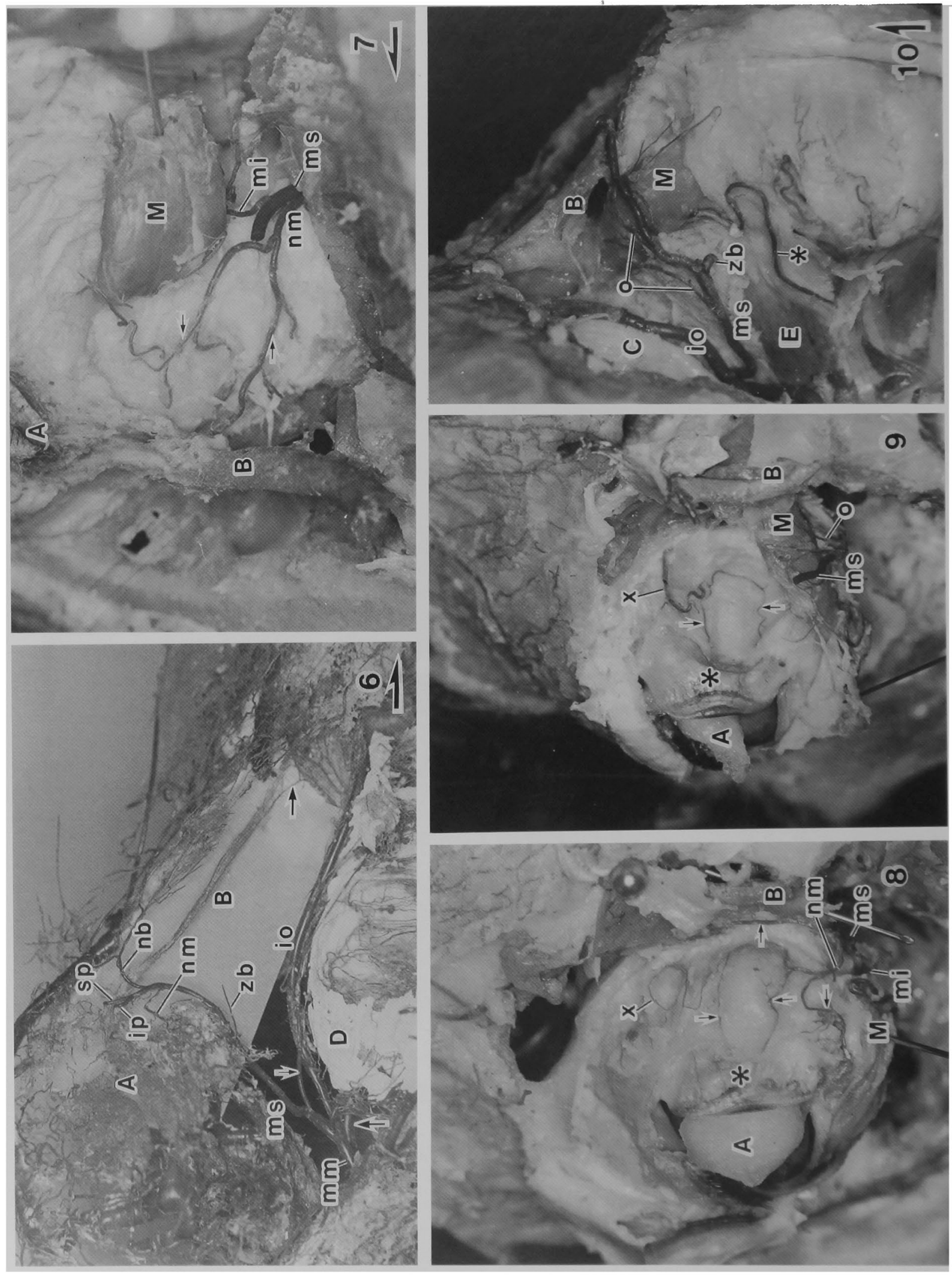




\section{Plate III}

Fig. 11. Lateral view of ramifications of the malar artery, right side. Dissection specimen. $\times 1$

The malar artery (ms) gives rise to the zygomatic ( $\mathrm{zb}$ ), the maxillary sinus (sb) branches and a common trunk between the superior (sp) and inferior (ip) medial palpebral arteries at the medial canthus, and finally becomes the nasal radical branch as a terminus. $\quad$ * : Periorbita, A: palpebral fissure.

Fig. 12. Lateral view of ramifications of the malar artery at the medial canthus, right side. Dissection specimen. $\times 15$

The malar artery (ms) gives rise to the maxillary sinus (sb), the accessory inferior oblique ( $\bigcirc)$ and the conjunctive ( $\uparrow$ ) branches. The superior palpebral artery (sp) gives rise to the nasolacrimal (nc) and the lacrimal canalicular $(\downarrow)$ branches. A: Palpebral fissure, B: nasolacrimal canal, M: obliquus inferior muscle.

Figs. 13 and 14. Lateral view of ramifications of the malar artery at the medial canthus, left side. Corrosion and dissection specimens, $\times 1$, and $\times 0.5$, respectively.

In Fig. 13, the malar artery becomes the nasal radical branch (nb) after giving off the medial superior (sp) and the inferior (ip) palpebral arteries and the infraorbital marginal branch (om). A: Palpebral fissure, $O$ : frontal branch of the superficial temporal artery, $\Delta$ : lateral superior palpebral artery, $\mathrm{X}$ : lateral inferior palpebral artery.

In Fig. 14, the nasal radical branch (nb) passes forwards lateral to the malaris muscle ( $*$ ), as a terminus of the malar artery. 

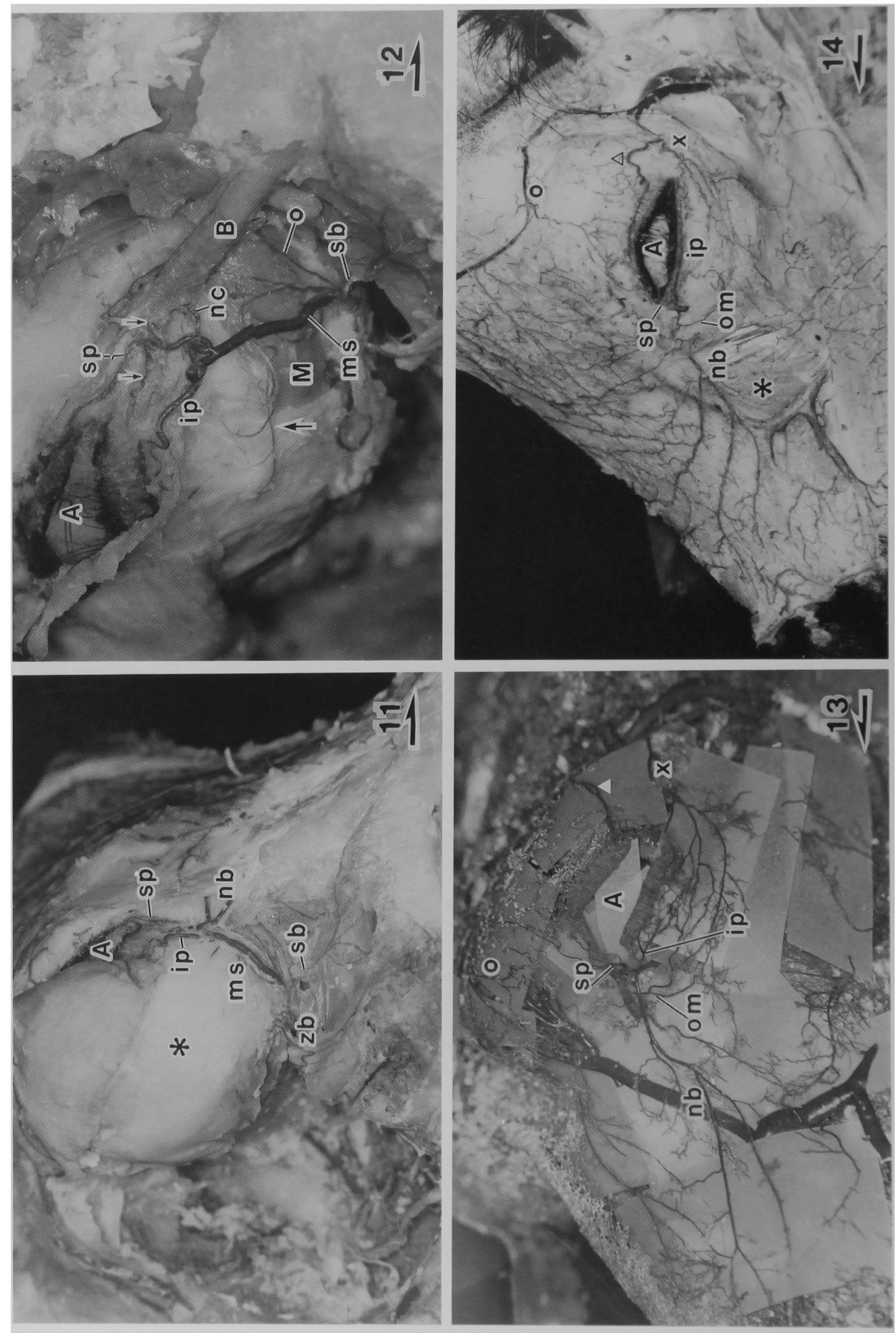